\title{
Sexualidade, gênero e afeto nos hospitais-colônias de hanseníase*
}

\section{Claudia Fonseca**}

Instigada pelos organizadores deste debate para a revista cadernos pagu, proponho nos próximos parágrafos refletir sobre a noção de sexualidade - "frequentemente imaginadas como própria das camadas médias urbanas, brancas ou 'Ocidentais'" questionando sua rentabilidade em lugares inesperados, a saber, populações tradicionais - indígenas, ribeirinhos, grupos populares, etc. Organizo minha discussão em torno de uma pesquisa em andamento sobre os hospitais-colônias para portadores de hanseníase que surgiram no Brasil no decorrer do último século.

É importante lembrar que os pacientes internados, na sua maioria, não eram das mesmas classes que os higienistas $e$ governantes que tinham planejado essas instituições. Parte dos pacientes chegou contra sua vontade, trazida pela polícia. Seguindo uma orientação lançada por Oswaldo Cruz e inscrita em legislação nacional desde o início dos anos 20 , a política era "sequestrar" os doentes - isto é removê-los da sociedade sadia e isolá-los, mesmo se fosse necessário o uso da força policial. Os que aderiam ao "modelo paulista" de internamento seguiam a risca essa orientação "sequestrando" tanto ricos como pobres (Cunha, 2010), que passariam a conviver durante seu tratamento na colônia. Entretanto, o mais comum era poupar doentes cujas

\footnotetext{
* Recebido para publicação em 4 de outubro de 2013, aceito em 15 de novembro de 2013.

** Professora no PPG em Antropologia Social, UFRGS. claudialwfonseca@gmail.com

1 Conforme Cunha (2010:942), “O chamado 'modelo paulista' determinou a exclusão de todos os doentes, independente do estágio e de sua forma clínica, distinguindo-se fortemente dos métodos adotados por médicos e autoridades de outros estados".
}

cadernos pagu (41), julho-dezembro de 2013:29-40. 
Sexualidade, gênero e afeto nos hospitais-colônias de hanseníase

famílias tinham condições para garantir o "internamento domiciliar" - internando nas colônias pessoas de origem mais humilde. A partir dos anos 40, existiam tratamentos que davam esperança de alta aos internados, permitindo um trânsito para dentro e para fora da instituição. Mas, curiosamente, muitos "exportadores", tendo recebido alta e saído da colônia, voltaram voluntariamente. Tratava-se em geral de pessoas de recursos modestos que não tinham aguentado as condições de discriminação e penúria enfrentadas fora da colônia. Dessa forma, entre os residentes da colônia, boa parte era do que poderiam ser considerados povos "tradicionais" - interioranos, ribeirinhos e de baixa renda.

1.

Foucault chamou atenção à lepra na sua discussão sobre formas de governo, associando-a a um "modelo de exclusão" em que certa categoria indesejável de pessoa seria segregada em um "território confuso para o qual se repelia a população da qual a cidade devia se purificar" (2001:56). Por outro lado, teria surgido, no século XVIII, uma nova filosofia de governo a partir de um "modelo de inclusão" calcado no combate à peste. Nesse,

não se trata de uma exclusão, trata-se de uma quarentena. Não se trata de expulsar, trata-se ao contrário de estabelecer, de fixar, de atribuir um lugar, de definir presenças, e presenças controladas. Não rejeição, mas inclusão. [...Trata-se, afinal de] Individualização, por conseguinte divisão e subdivisão do poder, que chega a atingir o grão fino da individualidade (id.ib.:57).

O desenho idealizado das colônias-hospitais de lepra refletia uma estranha combinação dos dois modelos - de segregação dos doentes, porém, em territórios nada confusos. As colônias surgiram numa época de afã eugênico e crença na engenharia social. Com o Estado avançando para dentro do domínio tradicional de filantropia religiosa, o governo brasileiro construiu, a partir dos anos 20, quarenta e poucos hospitais-colônias, 
abrigando na sua época auge mais de vinte mil pacientes ao todo. Seguiam os princípios de uma cidade modelar repleta de largas avenidas, igrejas, prefeitura, xadrez e cassino - além da enfermaria. Combinavam atributos de aldeia interiorana com os de uma instituição total (Goffman, 1963), onde junto com a esperança de um tratamento médico, as pessoas eram submetidas a normas que visavam um "policiamento exaustivo" por um poder político cujas "ramificações capilares" atingiriam "o próprio grão dos indivíduos, seu tempo, seu habitat, sua localização, seu corpo" e, podemos supor, seu comportamento sexual (Foucault, 2001:58-59).

Desde o início do século passado, nos debates sanitaristas que se alastravam pelo mundo, o comportamento sexual dos portadores de "lepra" se apresentava como um problema para o planejamento de políticas populacionais. Higienistas já tinham rejeitado ideias medievais que atribuíam a lepra a pecados (excessos ou transgressões) sexuais. Ainda estavam em dúvida sobre a transmissão do bacilo - se era passado durante as relações sexuais ou se podia ser herdado. Porém, para essa população, a reprodução em si era vista como problemática, pois, tornara-se praticamente consenso que, por causa do perigo de contágio, os "leprosos" não deviam cuidar de seus filhos "sadios". Não faltavam especialistas opinando que uma política de esterilização dos pacientes internados nas colônias diminuiria a necessidade de criar "preventórios" (orfanatos para esses filhos), reduzindo assim os encargos do Estado e das associações filantrópicas (Serres, 2004:60-62). ${ }^{2}$ Essas propostas não vingaram graças a argumentos baseados não só em sentimentos religiosos, mas também nas prováveis consequências para a moralidade sexual dos internos: "Havia o temor de que os doentes esterilizados, na certeza da impossibilidade da procriação, se tornassem promíscuos, possibilitando o aumento da propagação de doenças venéreas" (id.ib.:62).

2 No Japão, existia uma política de esterilização sistemática dos pacientes dos leprosários (cf Mendonca, 2009). 
Sexualidade, gênero e afeto nos hospitais-colônias de hanseníase

Pairava a assombração de uma sexualidade desregrada - $e$ a necessidade redobrada de fazer do sexo o pivô de um poder capilar. Assim, envidavam esforços para orientar a relação entre os sexos conforme critérios de saúde e moradia (ambos avaliados pela administração hospital - isto é, por médicos, irmãs religiosas, etc.):

o casamento entre doentes de lepra internados só será realizado com assentimento da administração dos estabelecimentos, que atenderá, salvo casos especiais, à sua oportunidade em relação ao estado da evolução da doença e à capacidade de seção destinada à habitação dos casados (Decreto $\mathrm{n}^{\circ}$ 7558, 11.11.1938, RS).

Os internos viviam em pavilhões segregados conforme idade e sexo, frequentando espaços igualmente segregados nas igrejas e nas alas de cinema. Organizavam-se bailes, mas em muitos locais, o costume era dançar mulher-com-mulher e homem-com-homem. Existiam medidas disciplinares proibindo até pessoas do mesmo sexo "passearem juntas" (Serres, 2004:155). Contudo, sempre cabe perguntar como essas regras eram recebidas pelos próprios internos. Procurando uma resposta, recorremos ao corpus crescente de literatura acadêmica que, em anos recentes, inclui cada vez mais depoimentos de residentes idosos das colônias (Serres, 2004; Mendonça, 2009; Faria, 2009;Videres, 2010). ${ }^{3}$

2.

Nos depoimentos de ex-internos, não faltam queixas, particularmente de homens, quanto à natureza opressiva das regras. Namorar sem permissão podia dar até um mês no

\footnotetext{
3 A diversidade de entrevistadores, assim como a cronologia vaga de eventos relatados, não permitiria uma sistematização conforme lugar e época descritos pelos depoentes sem uma ressalva metodológica que não cabe no espaço do presente texto. Por enquanto, lançamos mão desse material para evocar a pluralidade de respostas possíveis.
} 
"xadrez". Um residente se queixa que, diante das proibições dentro de sua colônia, os homens fugiam regularmente para visitar prostitutas na aldeia vizinha (fugas que também podiam dar cadeia). ${ }^{4}$ A dificuldade em casar era um dos grandes incentivos para escapar da instituição: "Comecei a me engraçar por essa daí (esposa). Como era proibido namorar lá dentro, nós fugimos durante uma festa..." (apud Videres, 2010:103). Sem dúvida, diante da patente impossibilidade de impedir as relações afetivas $e$ sexuais entre pacientes, os administradores reorientaram suas energias para o controle dessas atividades. Um ex-interno lembra como a chegada de um novo diretor trouxe mudanças: "Ele liberou um monte de coisas. Ele dizia que os homens podiam gostar das mulheres desde que não fizessem nenhuma besteira" (apud Videres, 2010:123).

Teoricamente, o diretor, tal como o pai nas famílias tradicionais, tinha controle sobre se e com quem os pacientes podiam casar. Diversas mulheres contam como o noivo levava seu pedido de casamento para essa autoridade administrativa, de quem podia eventualmente esperar, além da benção, uma casa para morar. Contudo, o diretor também podia negar permissão, alertando contra o comportamento dissoluto de um dos noivos, avisando que certo noivo não ia viver muito tempo ou ainda alegando que a gravidez só fazia piorar a condição da paciente. Nesse caso, não faltavam pessoas que contrariavam a orientação das autoridades:

[o diretor]... não queria que eu casasse. Ele dizia que eu ia piorar... só que eu já estava noiva com esse meu marido, que também era doente. Decidimos fugir para o Recife [para outra colônia]" (apud Videres, 2010:113).

${ }^{4}$ Autobiografia de Antonio Borges (2000). O autor menciona um trato entre internos e prostitutas de que caso uma das mulheres pegasse a doença, o interno seria obrigado a casar com ela. 
Sexualidade, gênero e afeto nos hospitais-colônias de hanseníase

Analistas demonstram como, no espaço da colônia, onde fiscais "sadios", i.e., externos, tinham medo de penetrar por causa do contágio, os internos tinham múltiplas maneiras para burlar as regras. Encontramos assim o lado avesso da "história oficial" (de controle $e$ abstinência). Olhares trocados durante a missa ganhavam corporalidade no mato e nas pequenas barracas (ranchinhos no Rio Grande do Sul) montadas por certos internos para permitir encontros privados. Em certos casos, estas últimas construções, queimadas repetidamente pelos administradores, eram reconstruídas com igual insistência (Serres, 2004; ver também Mendonça, 2012). Os homens lembram a facilidade com a qual conseguiam encontrar namoradas na colônia ("não tinha outra coisa para fazer"). As mulheres insistem que, chegando ainda "moças" no local, não foram morar nos pavilhões, e, sim, com Dona Fulana ou Beltrana (espécie de mãe de acolhimento), pois era a única maneira de "resguardar sua inocência". 5 , aparentemente rolavam muitas fofocas sobre as "complicações" que dava o namoro "lá dentro": "...dava muito incômodo, os encontros clandestinos, vamos dizer assim, estava ficando uma coisa viciosa, nem se escondiam mais" (apud Serres, 2009:236).

As histórias são ainda mais sugestivas no que diz respeito às pessoas já casadas. O diagnóstico de hanseníase em apenas um dos esposos condenava o casal a uma separação abrupta. Os não internados tinham que encontrar uma maneira para sobreviver com a economia doméstica cortada pela metade. Porém, os cônjuges internados padeciam ainda mais da separação. As visitas familiares eram esporádicas e pouco satisfatórias. Um homem conta como, depois de duas visitas, foi abandonado pela mulher: "Ela se informou com o médico da doença, mas vixe Maria! O médico fez o maior bicho do mundo, foi ele quem fez a mulher se afastar de mim" (apud Videres, 2010:91). Outro diz que mesmo quando a mulher vinha visitar, não era permitido nem que sentasse na cama: "Acho tudo isso uma besteira, porque depois a

${ }^{5}$ Entrevistas concedidas à CF por um ex-interno, Belém, 2012. 
gente foi morar junto, tivemos esses meninos tudinho e nunca pegaram doença nenhuma. Pra que todo aquele pavor!" (apud Videres, 2010:123).

Quando as pessoas procuravam consolo afetivo nos limites de sua nova vida, podiam sofrer acusações morais: "Às vezes, internava uma mulher séria, mas o tempo e a separação do marido iam calejando, às vezes, uma necessidade de sexo, a ocasião faz o ladrão" (apud Serres, 2009:236). Não era inusitado o paciente assumir uma nova identidade ao entrar na colônia, ostensivamente, para permitir à sua família escapar do estigma de ter um parente com lepra. Entretanto a nova identidade também facilitava o recasamento de pessoas já casadas (Serres, 2004).

3.

Ao tentar reconstruir as atitudes dos internos durante o auge das colônias, certos pesquisadores enfatizam a cooperação, sugerindo que os residentes acabavam interiorizando as normas da instituição, as realizando como se fossem escolhas individuais (Borges, 2007). Outros enfatizam como os internos traçavam linhas de fuga, criando brechas para escapar do poder disciplinar (Mendonça, 2012). De uma maneira ou outra, podemos deduzir que a experiência de internação produzia efeitos, contribuindo para moldar atitudes, inclusive diante do sexo e do amor. A autobiografia de certa mulher do interior de Acre, internada quatro vezes ao longo de sua vida, nos ajuda a pensar esses efeitos.

É pelo fim dos anos 50 que Maria Lúcia, ainda menina, é levada à força para o leprosário em Rio Branco (Regis, 1983). No último dia de seus dois anos de internamento, inicia com Francisco, outro interno adolescente, um "amor de infância" "era só de olhar um para o outro de longe". Francisco pede para ela aguardar que ele também saia da instituição para eles estarem juntos. Com a reinternação da moça alguns anos mais tarde e o reencontro com Francisco, a relação deles - sempre sob a vigilância das irmãs religiosas que administram o lugar - evolui para um "amor puro e verdadeiro", entre a moça e seu "príncipe 
Sexualidade, gênero e afeto nos hospitais-colônias de hanseníase

encantado". Entretanto, com uma melhora de saúde, ela sai mais uma vez da colônia e acaba fazendo sua vida, casando e tendo filhos, com outro moço, vizinho de sua família no interior.

Apesar de Maria Luiza ser "apaixonada" por seu marido, a vida de casal, assim como sua saúde, vai mal diante de uma rotina diária de trabalho (na roça e na pesca) e penúria. $\mathrm{O}$ marido, analfabeto e de parcos recursos, não consegue prover as necessidades da família e ela, com o avanço de sua doença, não consegue "ajudar" - lavando para fora ou pegando na enxada. É durante uma nova internação de alguns meses que ela redescobre o amor de seu marido que, aliviado do peso de ser provedor, faz prova de uma fidelidade amorosa nas suas visitas semanais à esposa. Contudo, o casal acaba se desfazendo, e alguns anos mais tarde, Maria Lúcia, tendo vivido outras decepções amorosas e já com sequelas mais sérias da doença, volta a procurar "uma vaga" na colônia. Essa vez, ela segue os conselhos de conhecidos internados, se juntando com "uma pessoa de muita responsabilidade" - um homem que "não bebia, não jogava, não gostava de festas, era muito trabalhador, humilde e solteiro". Com a benção do bispo, essa "amizade passageira" se torna séria e o casal sai da colônia para poder "se unir". Maria Lúcia se pronuncia sobre essa relação que, com o término do livro, prevê uma nova fase de vida: "... não tinha um lar com [meu marido $e$ namorados anteriores]. O motivo da doença não nos uniu. (...) Deveria fazer mais uma tentativa, agora diferente, com um doente que fosse igual a mim" (Regis, 1983:118).

Ao longo da vida de Maria Lúcia, a experiência de internação na colônia figura não como algo "determinante", mas como um elemento que, junto com a influência dos pais e da vizinhança, vai compondo um cenário afetivo que inclui amor romântico e paixão sexual assim como, afinal, uma relação conjugal "sensata". Sua própria identidade que inclui (entre muitas outras possibilidades) a de ser "um doente" ganha novas tintas dentro das circunstâncias da colônia. Não se trata da submissão brutal à norma institucional, mas de uma educação 
gradativa dos sentimentos que culmina na escrita da autobiografia onde "o grão fino da individualidade" de Maria Lúcia é submetido ao olhar (normalizador?) de seu leitor.

A história de Maria Lúcia chama atenção para ainda outra dimensão importante dessa análise - a maneira com que a vivência afetiva se articula às dependências mútuas implicadas na organização do espaço e das tarefas domésticos. Por exemplo, em certas colônias, existiam apenas pavilhões coletivos, tornando difícil qualquer relação duradoura de casal. Em outras, o pequeno número de casas disponíveis exigia a convivência prolongada de casais de diferentes gerações ou proveniência. De qualquer maneira, para a maioria, era afastada a esperança de encontrar dentro da colônia um espaço de "lar, doce lar". Ainda mais intrigante, porém, é pensar a particular organização das tarefas familiares.

Não obstante imagens de propaganda que, nos anos 40, mostravam o entusiasmado empenho dos internos em atividades "normais" - as mulheres lavando roupa, os homens capinando suas lavouras ${ }^{6}-$, as condições de saúde e vida na colônia nem sempre permitiam tal replicação da vida tradicional. As mulheres, apesar de dar à luz, não cuidavam de seus filhos; e, já que boa parte das refeições se realizava nos refeitórios coletivos, nem sempre cuidavam da cozinha. Os homens também tinham alternativas limitadas. Um ex-interno se queixava que trabalhava na enfermaria por um salário irrisório, mas sem essa atividade teria "morrido de tédio" (Maciel et al, 2003). O provedor principal de todos os residentes (que, aliás, nem sempre cumpria essa tarefa a contento) era a administração da Colônia: quem não comia no refeitório devia receber as refeições ou pelo menos rancho semanal em casa. Exatamente como essa "outra" organização doméstica reconfigurava os papéis masculino e feminino e como essa reconfiguração pesava na vida afetiva, permanecerá uma

\footnotetext{
${ }^{6}$ Inauguração do Hospital Colônia de Itapuã, em 1940. Disponível em: $<$ https://www.youtube.com/watch?feature = player embedded\&v $=$ TKHvGxzD5E>
} 
Sexualidade, gênero e afeto nos hospitais-colônias de hanseníase

pergunta para futuras pesquisas. Aqui, basta ponderar como, durante longo tempo, a vida de casal era considerada incompatível com a permanência dentro da colônia.

4.

Na visão dos higienistas, existia certa vizinhança entre lepra e sexualidade - tanto que, em 1921, criou-se a Inspetoria da Profilaxia da Lepra e Doenças Venéreas para lidar com o que eram vistas como duas epidemias que ameaçavam a nação. Ironicamente, não se encontra essa mesma "vizinhança" na história da saúde pública. Existem pesquisas brilhantes sobre como a preocupação com doenças venéreas no Brasil foi alvo de discussões científicas e políticas que resultaram na vigilância cada vez maior da sexualidade (em particular) masculina (Carrara, 1996). Mas, a lepra parece ter sido deixada para o lado "dessexualizado" nas discussões acadêmicas. Na obra clássica de Souza Araújo, a História de lepra no Brasil (1946), não há referência direta à sexualidade. $\mathrm{E}$ até hoje, não obstante descrições interessantes de namoro e casamento nas colônias, esses temas continuam periféricos (com a exceção de Borges, 2007). Inexistem discussões sobre relações de gênero e a sexualidade aparece apenas na literatura de enfermagem (Santos et al, 2010). Será que essa relativa carência de material não se deve à crença difundida no senso comum de que, para portadores de doenças graves, preocupações sobre a vida afetiva e sexual devem constar em segundo lugar, atrás das preocupações com saúde? (ver Shuttleworth, 2001).

No presente ensaio, inverti o esquema de análise usual $e$ coloquei os afetos e a sexualidade em primeiro plano. Ciente da perspectiva foucaultiana que vê a "sexualidade" como parte integrante de certo dispositivo de controle, propus, em um primeiro momento, mostrar o quanto certa filosofia de governo concebia a vida afetiva e sexual dos portadores de lepra como um problema "populacional", elaborando políticas condizentes de intervenção. Em um segundo momento, lancei mão do farto 
corpus de depoimentos de ex-internos para evocar maneiras em que o próprio interno lidava com a disciplina da colônia. Sugiro que as intervenções médica, religiosa e administrativa tão presentes nas colônias produziram efeitos - servindo para "normalizar" comportamentos e levar o "dispositivo" da sexualidade para dentro de categorias (antes) marginais da população; por outro lado, trouxeram consequências inesperadas. Não só os internos acionavam estratégias inspiradas em outros repertórios "culturais" para se furtar às regras da administração. Também, o próprio desenho das colônias quanto à moradia e organização de tarefas domésticas exigia considerável ajuste de ideias tradicionais de gênero - tanto entre administradores, quanto entre internos. Em suma, refletir sobre a articulação entre sexualidade, gênero e afeto na minha pesquisa em andamento se mostrou um exercício interessante capaz de abrir novas (e, sem dúvida, profícuas) pistas de investigação.

\section{Referências bibliográficas}

ARAUJo, Heraclides Souza. História da lepra no Brasil. Rio de Janeiro, Imprensa Nacional, 1946.

Borges, Antônio. Fragmentos da vida. Salvador, Ed. Helvécia, 2000.

BORGES, Viviane Trindade. "Casamento, maternidade e viuvez: memórias de mulheres hansenianas". Revista Brasileira de História. São Paulo, vol. 27, n 54, 2007, pp.109-125.

CARRARA, Sergio. Tributo a Vênus: A luta contra a sífilis no Brasil, da passagem do século aos anos 40. Rio de Janeiro, FIOCRUZ, 1996.

CUNHA, Vivian da Silva. Isolados "como nós" ou isolados "entre nós"? A polêmica na Academia Nacional de Medicina sobre o isolamento compulsório dos doentes de lepra. História, Ciências, Saúde Manguinhos, vol.17, n4, Rio de Janeiro, Fiocruz, 2010, pp.939-954.

FARIA, Amanda Rodrigues. Hanseníase, experiência de sofrimento e vida cotidiana num ex-leprosário. Dissertação de mestrado, Antropologia Social, UnB, Brasília, 2009. 
Sexualidade, gênero e afeto nos hospitais-colônias de hanseníase

FOUCAULT, Michel. Os anormais. São Paulo, Martins Fontes, 2001.

GOFFMAN, Erving. Stigma: Notes on the management of spoilt identity. Englewood cliffs, N.J., Prentice Hall, 1963.

MACIEL, Laurinda Rosa; OliveIRA, Maria Leide Wand-del-Rey de; GALlo, Maria Eugênia N. e DAMASCO, Mariana Santos. Memória e história da hanseníase no Brasil através de depoentes (1960-2000). História, Ciências, Saúde - Manguinhos vol.10, supl.1, Rio de Janeiro, Fiocruz, 2003, pp.308-336. Disponível em: <http://www.scielo.br/pdf/hcsm/v10s1/a15v10s1.pdf>.

MENDONÇA, Ricardo F. Reconhecimento e deliberação: as lutas das pessoas atingidas pela hanseníase em diferentes âmbitos interacionais. Tese de Doutorado em Comunicação Social, UFMG, Belo Horizonte, 2009.

MENDONÇA, Ricardo F. Táticas cotidianas e ação coletiva: a resistência das pessoas atingidas pela hanseníase. Varia História 28 (47), pp.341360, 2012.

REGIS, Maria Lucia. A garra de viver, amar e conviver feliz. Brasília, João Felipe de Medeiros \& Elizabeth Skvamavicius, 1983.

SALES, Jaqueline Carvalho e Silva. Sexualidade de pessoas quem vivem com hanseníase: percepção e repercussões. Revista de enfermagem, 7(2), Recife, UFPE on line , 2013, pp.460-466.

SANTOS, Tatiana M. et al. Hanseníase: implicações na Sexualidade do portador. Hansenologia Internationalis 35 (2), 2010, pp.27-32.

SERRES, Juliane Conceição Primon. "Nós não caminhamos sós": o hospital colônia Itapuã e o combate à lepra no Rio Grande do Sul (1920-1950). Dissertação de Mestrado em Estudos Históricos Latino Americanos - UNISINOS, São Leopoldo, 2004.

ShUTtLeWORTH, Russell. Exploring Multiple Roles and Allegiances in Ethnographic Process in Disability Culture. Disability Studies Quarterly, vol. 21, n 3, Summer 2001, pp.103-113.

VIDERES, Arieli Rodrigues Nóbrega. Trajetórias de vida de ex-portadores de hanseníase com histórico asilar. Dissertação de Mestrado em Enfermagem - UFR, 2010. 